\title{
O Hipupiára e a Poética: uma reflexão sobre os limites do verossímil e da autópsia no século XVI
}

\author{
Marcello Moreira* \\ Manoela Freire Correia*
}

\begin{abstract}
Resumo
O estudo tem, como matéria, práticas de descrição e também uma imagem manuscrita, e outra, análoga, impressa, que compõem livros de Pero de Magalhães de Gandavo, intitulado, o primeiro - manuscrito depositado nos dias de hoje no Museu do Escorial -, "Historia da prouincia Sancta Cruz, a que ulgar mente chamamos Brasil: feita por Pero Magalhães de Gandauo, dirigida ao muito Illustre Sñor Do Lionis Pereira, e, o segundo, Historia da prouincia Sãcta Cruz a que ulgarmente chamamos Brasil: feita por Pero de Magalhães de Gandauo dirigida ao mui Illus $^{\text {mo }}$ Dom Lionis Pa gouernador que foy de Malaca e das demais partes do Sul da India" encontrado no acervo da Biblioteca Nacional do Rio de Janeiro. Objetiva-se compreender como a figuração do monstro Hipupiára, presente nas duas versões do livro de Pero de Magalhães de Gandavo, acima mencionados, é constituída poética e retoricamente, evidenciando-se processos de analogia, fundamentais para a composição dos corpora monstrorum, e a relação entre história, poética, autópsia e verossimilhança.
\end{abstract}

Palavras-chave: Pero de Magalhães de Gandavo. História da província Santa Cruz. Hipupiára. Poética. Retórica.

\section{The Hipupiára and the Poetics: a reflection on the limits between likelihood and autopsy in the 16th Century.}

\begin{abstract}
This study delves, on one hand, into the description practices; on the other, a handwritten image and the analogous printed materials that compose the books by Pero de Magalhães Gandavo, entitled: (i) Historia da prouincia Sancta Cruz, a que ulgar mente chamamos Brasil: feita por Pero Magalhães de Gandauo, dirigida ao muito Illustre Sñor Do Lionis Pereira (History of the Sancta Cruz Province, vulgarly referred to as Brazil: written by Pero Magalhães de Gandavo, directed at His Eminence Sñor Do Lionis Pereira) - a manuscript kept today at the Escorial Museum; and (ii) Historia da prouincia Sãcta Cruz a que ulgarmente chamamos Brasil: feita por Pero de Magalhães de Gandauo dirigida ao mui Illus ${ }^{\mathrm{mo}}$ Dom Lionis $\mathrm{P}^{\mathrm{a}}$ gouernador que foy de Malaca e das demais partes do Sul da India (History of the Sãcta Cruz Province, vulgarly referred to as Brazil, written by Pero Magalhães de Gandavo, directed at His Eminence Dom Lionis Pereira, former governor of Malacca and other regions in the South of India), found in the archives of the National Library of Rio de Janeiro. Our aim is to understand how the manifestation of the Hipupiára monster is constructed both poetically and rhetorically, highlighting the analogy processes, essential to compose the corpora monstrorum, as well as the relationship among history, poetics, autopsy, and verisimilitude.
\end{abstract}

Keywords: Pero de Magalhães de Gandavo. History of the Sancta Cruz Province. Hipupiára. Poetics. Rhetoric.

\footnotetext{
* Universidade Estadual do Sudoeste da Bahia. Professor Pleno de Letras Luso-Brasileiras e de Historiografia e História Literária. Bolsista de Produtividade em Pesquisa do CNPq.

** Universidade Estadual do Sudoeste da Bahia. Mestre pelo Programa de Pós-Graduação em Memória: Linguagem e Sociedade
} 
(I)

Aristóteles, logo ao princípio da Poética, ao exemplificar o que entendia por imitação, assevera que poemas, como epopeia e tragédia, e também artes musicais, como aulética, citarística e siríngica, são todos eles imitativos (ARISTÓTELES, 1994, p. 103), conquanto difiram uns dos outros em três aspectos, sobre que passa então a discorrer: primeiramente, declara que diferem por imitar por diversos meios; em segundo lugar, diferem por imitar distintos objetos, e, por fim, diferem por imitar por diferente modo (ARISTÓTELES, 1994, p. 103). A diferença entre objetos diz respeito à possibilidade de se imitarem caracteres agentes que se destacam ou pela excelência da virtude ou pela baixeza do vício:

Mas como os imitadores imitam homens que praticamalguma acção, e estes, necessariamente, são indivíduos de elevada ou de baixa índole, porque a variedade dos caracteres só se encontra nestas diferenças [e, quanto ao carácter, todos os homens se distinguem pelo vício ou pela virtude] (ARISTÓTELES, 1994, p. 105).

Os mesmos objetos de imitação, contudo, podem ser imitados por diversos meios. Como Aristóteles nos ensina na Poética, ao discorrer sobre a música dos aulos e a dos citaristas, comparando-as com a arte dos dançarinos, diz que todas são imitações, mas aulética, citarística e siríngica imitam por meio da harmonia e do ritmo, enquanto dançarinos imitam caracteres, afetos e ações exclusivamente por meio do ritmo (ARISTÓTELES, 1994, p. 103). Quanto àqueles que pintam, tomam para si a diversidade de caracteres, e houve pintores que preferiram imitar homens superiores, como Polignoto; inferiores, como Pausão, e houve os que imitaram homens como nós, especialidade de Dionísio (ARISTÓTELES, 1994, p. 105). A ideia de "imitação" é fundamental não apenas para distinguir o que é poético, mas para produzir diferença frente àquilo que não o é: aprendemos, por exemplo, que o verso na reflexão aristotélica sobre poesia não define o propriamente poético, pois há obras como as de Heródoto, que, se postas em versos, nem por isso deixariam de ser históricas (ARISTÓTELES, 1994, p. 115). A imitação, diferentemente da história, não trata do que de fato ocorreu, mas daquilo que poderia acontecer segundo a necessidade e a verossimilhança. Estas, "necessidade" e "verossimilhança", dizem respeito a uma ideia central da reflexão aristotélica sobre a poesia, que é aquela da "unidade do mito". Segundo Aristóteles, o mito deve ser uno no poema trágico, na epopeia e nas demais espécies poéticas, e por "unidade" não quer ele significar que as ações devam respeitar a uma só pessoa, porque muitas ações de uma só pessoa não são passíveis de reunião em uma unidade qualquer (ARISTÓTELES, 1994, p, 114). Como exemplo de falta de unidade e, portanto, de imperfeição em termos de composição, refere poemas como a Heracleida e a Teseida, em que muitas são as ações de uma só personagem, mas disjuntas: “Assim, parece que tenham errado todos os poetas que compuseram uma Heracleida ou uma Teseida ou outros poemas que tais, por entenderem que, sendo Héracles um só, todas as suas ações haviam de constituir uma unidade" (ARISTÓTELES, 1994, p. 114).

A unidade de mito é fundamental para que o poema seja perfeito e Aristóteles nos demonstra o que entende por essa perfeição ao exemplificá-la com os poemas homéricos; ele assevera que Homero, por engenho natural, não poetou todos os sucessos da vida de Ulisses, e, por conseguinte, não fez referência ao fato de ter sido ele, Ulisses, ferido no Parnaso, ou ainda de ter se fingido louco no momento em que se reuniu ao exército, e isso pela simples razão de que, por ter sucedido uma dessas coisas, não seguia que as outras todas participantes do poema teriam também de suceder: "Porque, de haver acontecido uma dessas coisas, não se seguia necessária e verossimilmente que a outra houvesse de acontecer, mas compõe entorno de uma ação una a Odisseia - una no sentido que damos a esta palavra - e de modo semelhante a Ilíada” (ARISTÓTELES, 1994, p. 115).

A ideia de "necessidade" implica, portanto, que "todos os acontecimentos se devem suceder em conexão tal que uma vez suprimido ou deslocado um deles, também se confunde ou mude a ordem do 
todo" (ARISTÓTELES, 1994, p. 115), pois não pode fazer parte de um todo aquilo que, ao ser retirado dele, não lhe causa dano ou falta nenhuns. Se poesia, portanto, se perfeita, implica a postulação do princípio de "unidade", o que pensar do gênero histórico, em que os agentes são múltiplos não Heracleida, Teseida ou Odisseia - e várias são também as ações? Aristóteles afirma ainda que a história trata do sucedido e a poesia do que poderia suceder e essa diferença é de fundamental importância para se entender o "universal da poesia" segundo o Estagirita, porque ele residiria justamente nessa "possibilidade de sucedimento" de acordo com necessidade e a verossimilhança ou probabilidade. A ideia de que a poesia trata do universal, contrariamente à história, que trata do particular, é demonstrada em Aristóteles por remissão ao elemento dóxico da relação entre caráter agente e evento: o caráter em Aristóteles, ao realizar uma ação, só deve empreender aquelas que sejam afeitas à sua natureza, de modo que nos pareçam verossímeis, e, segundo a unidade do mito, necessárias (STE. CROIX, 1992, p. 21). Quando a Poética é lida nos séculos XVI e XVII na Europa do Ocidente e se empreendem os seus muitos comentários, a interpretação do universal da poesia sempre se dá aquando da discussão do que é verossimilhança: discorre-se, por exemplo, sobre o rei e são apresentados os preceitos que devem regrar a composição desse caráter agente na tragédia e no poema épico por meio do fornecimento de lugares comuns opinativos sobre o que um rei deveria ser, pondo-se de parte como reis particulares e empíricos de fato agem (MOREIRA, 2011 p. 340-341). A história, apesar de menos filosófica do que a poesia, porque trata do particular, nem por isso deixa de impactar o opinativo em que se baseia a verossimilhança, porque é capaz de mudar os endoxa estabelecidos pelo acúmulo de exempla que os denegam (WOODRUFF, 1992, p. 73-74). Pode-se dizer, portanto, que o particular da história, concebido como lição histórica (Historia magistra vitae), acaba por alterar no transcorrer do tempo o dóxico da verossimilhança (MOREIRA, 2011, p. 340). O gênero histórico não opera com a mesma obrigação de adesão do narrador ao contrato enunciativo da poesia; nela, na poesia, o poeta pode representar uma sequência ideal de eventos, tais como deveriam ocorrer de acordo com as leis que governam o "comportamento humano" (STE. CROIX, 1992, p. 24). A história tem por dever aderir ao sucedido, podendo ele ser ou não verossímil (ARISTÓTELES, 1994, P. 116-117), e as ações por ela representadas são múltiplas, efetuadas por um grande número de caracteres, sem unidade, em que predomina o episódico; este é, sem sombra de dúvida, o recurso discursivo que implica fratura na ideia de "unidade", própria da poesia.

(II)

O episódico implica justaposição tanto em Historia da prouincia Sancta Cruz, a que ulgar mente chamamos Brasil: feita por Pero Magalhães de Gandauo, dirigida ao muito Illustre Sñor Do Lionis Pereira, pronto antes de 1573 (HUE, 2018, p. 208), quanto em Historia da prouincia Sancta Cruz, a que ulgar mente chamamos Brasil: feita por Pero Magalhães de Gandauo, dirigida ao muito Illustre Sñor Do Lionis Pereira e Historia da prouincia Sãcta Cruz a que ulgarmente chamamos Brasil: feita por Pero de Magalhães de Gandauo dirigida ao mui Illus ${ }^{\mathrm{mo}}$ Dom Lionis $\mathrm{P}^{\mathrm{a}}$ gouernador que foy de Malaca e das demais partes do Sul da India (1576), e é elemento estruturante da composição, o que se torna evidente em seção da narração em que nos é apresentado o "caso" do Hipupiára. Ao lermos nos dias de hoje os relatos de Pero de Magalhães de Gandavo, parece-nos inverossímil a figura do monstro que nos é descrita, mas ela parecia não só verossímil ao tempo em que foi noticiada, mas verdadeira, o que significa fazer ela parte de outro conjunto de opiniões tidas por tais entre os homens sábios, como dizia Aristóteles. Passemos aos relatos em que o Hupupiára comparece, para entendermos seus componentes poéticos, retóricos e sua particularidade histórica.

Nos dois livros de Pero de Magalhães de Gandavo, que acima citamos, ${ }^{1}$ este se propõe a fazer o

1 Há do livro de Pero de Magalhães de Gandavo quatro versões, estudadas detidamente por Sheila Moura Hue em artigo intitulado "Imagens do Brasil para além de Gandavo". Nele, a pesquisadora da UERJ nos demonstra que o livro foi composto em duas fases, sendo que na primeira delas foram redigidas duas versões, intitulada a primeira Tratado da 
"retrato" de um monstro marinho, chamado Hipupiára, na língua indígena, que quer dizer "demônio d'água", que foi morto por um mancebo, filho de um Capitão cujo nome era Baltasar Ferreira, na Capitania de São Vicente, em 1564. Segundo Sheila Hue, numerosos missionários e cronistas "Falam dos homens marinhos ou ipupiaras", dentre os quais se podem citar "o Pe. José de Anchieta, Gândavo, Fernão Cardim, Gabriel Soares de Sousa, Pe. Francisco Soares e Manuel Bernardes. Ipupiara quer dizer “coisa má que anda n’água” (HUE, 2004, p. 127).

O relato sobre o episódio do Hupupiára principia pelo uso, por parte do cronista, de artifícios retóricos utilizados para tornar os leitores atentos, dóceis e benevolentes:

Foi cousa tam noua, \& tam desusada aos olhos humanos, a semelhança daquelle fero \& espantoso monstro marinho que nesta prouincia se matou no anno de $1564 \mathrm{q}$ ainda que por muitas partes do mundo se tenha ja noticia delle, nam deixarey todauia de a dar aqui outra vez de nouo, relatando por extenso tudo o q acerca disto passou (GANDAVO, 1576, p. 30).

Do trecho extratado, assinalamos que o narrador, em primeiro lugar, promete dizer coisas novas e incríveis, "desusadas aos olhos humanos". Em segundo lugar, ele apresenta rapidamente o monstro, qualificando-o de feroz e assustador (espantoso), a fim de deixar os leitores com boa disposição para ler, porque causa curiosidade e adesão àquilo que se lê o que é fora do comum (monstruoso). Além disso, o cronista informa o tempo em que ocorreu o episódio narrado, para tornar a narração não apenas verossímil, mas verdadeira. A credibilidade é fruto de procedimento de notação, próprio do gênero histórico, em que se especificam o tempo e lugar do ocorrido: o monstro apareceu na Capitania de São Vicente, no Estado do Brasil, em 1564; tempo e lugar tornam particularíssima a aparição do Hipupiára, singularizando-a. Declarar que houve testemunhos da aparição do monstro e que se conheceu pessoalmente uma ou várias testemunhas é tornar a autópsia histórica um critério de validação da informação: viu-se o monstro e conheci os que o viram, é o que assevera Gandavo. Depois de termos aprendido com os historiadores do século XIX que há diferença entre imaginação histórica e prova histórica (BURCKHARDT, 2003), perguntamo-nos qual a liminaridade entre imaginação e prova em escritos históricos do século XVI, questão que ainda carece de resposta e de que não trataremos aqui (GINZBURG, 1991, p. 216). O que não se pode fazer, e isso também aprendemos com historiadores como Michel de Certeau (1986) e Paul Veyne (1998), é crer que haja falácia referencial porque o Hipupiára comparece em um relato "histórico", não sendo ao mesmo tempo "verdadeiro". O que está em jogo não é a relação entre história e particular ou entre história e verdade, mas o estatuto do que se concebia como "realidade" no século XVI. Mais, o que está em questão é justamente a noção de "prova", outra nos Quinhentos frente ao que se passou a entender como tal a partir do metodismo da escola positivista no século XIX (CERTEAU, 1886, p. 67-68). E cremos de nada adiantar o tentar nos dias de hoje relacionar o monstro de Pero de Magalhães de Gandavo a um animal, conhecido em nossos dias, como, por exemplo, um leão-marinho, porque é preciso ler a novidade do monstro no tempo em que se o nomeava e se o sabia assim, validada a crença em sua existência por uma "experiência".

Leiamos o fragmento acima excertado de um dos livros de Pero de Magalhães de Gandavo para compreender como a ideia de "autópsia" se articula enquanto discurso. Principia a descrição do Hipupiára com a introdução da "matéria”, tipicamente exordial: afirma-se que o monstro que aparecera era "cousa tam noua e tam desusada aos olhos humanos", que causava espanto sua "semelhança", ou

Província do Brasil, dedicada à Rainha Dona Catarina de Áustria, e, a segunda, intitulada Tratado da Terra do Brasil, ao Cardeal Infante Dom Henrique. Segundo Sheila Hue, de quem retiramos as informações acima, a obra de Pero de Magalhães de Gandavo "passa por uma extensa reformulação - a segunda fase do processo -, da qual surgem mais duas versões: antes de 1573 já está pronta a primeira redação da História da província Santa Cruz a que vulgarmente chamamos Brasil, registrada no manuscrito IV.28 da Real Biblioteca do Mosteiro do Escorial, seguida da versão definitiva impressa em Lisboa por Antônio Gonçalves" (HUE, 2018, p. 208). Em nosso estudo, só nos valemos das versões produzidas durante a segunda fase de composição da obra. 
seja, sua compleição, que era "fera" e "espantosa". A estrutura exordial serve para unir, em um mesmo argumento persuasivo, duas coisas que comumente se excluem, ou seja, "coisa tão nova e desusada" e crença fundada em procedimento autopsial; os olhos humanos só veem, é o que Pero de Magalhães de Gandavo deixa implicado, aquilo que costumeiramente veem, estando percepção e visão fundadas em uma consuetudo do olhar. É, por conseguinte, espantoso, que haja "semelhança" tão dessemelhante a tudo o que já vimos. A autópsia, que qualifica a argumentação como propriamente histórica, precisase ao especificar o locum ou lugar da ocorrência do evento: matou-se o monstro marinho "nesta prouincia", ou seja, em São Vicente, e o tempo por seu turno precisa-se com a especificação do ano, ou seja, "em 1564". A ocorrência foi tão extraordinária, e de fato o foi, porque, se não o fosse, não seria "nova", que "por muitas partes do mundo" há notícia dela; mas, mesmo que haja novas sobre essa novidade aparecida em São Vicente, o cronista não deixará "todauia de a dar aqui outra vez de nouo, relatando por extenso tudo o q acerca disto passou". Mas por que relatar por extenso tudo o que se passou em São Vicente, em 1564, se há em muitas partes do mundo informação circulando sobre o sucedido? Pero de Magalhães de Gandavo explica-se do modo que segue: "Porque na verdade a mayor parte dos retratos, ou quasi todos, em que querem mostrar a semelhança de seu horrendo aspecto, andam errados, \& alem disto, contase o successo de sua morte por differentes maneiras, sendo a verdade huma só, a qual he a seguinte [...]" (GANDAVO, 1576, p. 30).

Pero de Magalhães de Gandavo remete às notícias que há em circulação em seu tempo sobre a aparição do Hipupiára para, em seguida, contrapô-las àquela que ele dá a público em seu livro sobre a Província de Santa Cruz. Nessa contraposição, há por mais de uma vez estruturas binárias de argumentação, em que se opõem "a semelhança de seu horrendo aspecto" falsa à que é verdadeira, e, também, o falso "successo de sua morte" àquele que é o único em que se pode crer, porque é o único que atende ao testemunho do sucesso. Sendo "a verdade huma só", porque vista, testemunhalmente não há como haver disparidade nos relatos da aparição do monstro, porque essa dispersão de informação é contrária à autópsia e à sua natureza de prova. O uso da autópsia como argumento de validação de "provas" é prescrição corrente em tratados de retórica antigos, e também nos séculos XVI e XVII, como no Retórica a Alexandre, cuja autoria é incerta, sendo ora atribuída a Aristóteles, ora a Anaxímenes. Prescreve-se que "em apoio de fatos implausíveis" devem-se aduzir razões "que farão os acontecimentos sustentados por nós parecerem prováveis de ter ocorrido". Como fazer para que uma coisa implausível, no entanto, pareça verdadeira? Na Retórica a Alexandre assevera-se que "É preferível omitir quaisquer ocorrências demasiado improváveis", mas, se o historiador ou o cronista se virem obrigados a "apresentá-las", deve mostrar que as "conhece como fatos e mencionálas muito ligeiramente [...], e prometer que demonstrará a verdade ou a justiça, ou algo semelhante [...]" ([ARISTÓTELES], 2012, p. 75). Pero de Magalhães de Gandavo, em atendimento a prescrições retóricas de seu tempo, afirma que conhece os fatos e deixa claro que, mesmo peritos, com frequência, revelam-se equivocados ao dar conta desses acontecimentos, afinal a maior parte dos retratos ou quase todos que querem mostrar o horrendo aspecto do monstro andam "errados". Com isso, Gandavo torna patente o próprio intuito de dizer a "verdade do ocorrido", a qual é uma só: a dele. Quando da negação da validade das informações que circulam sobre o Hipupiára em "outras partes”, Pero de Magalhães de Gandavo obviamente faz remissão, conquanto não os nomeie, a autores contemporâneos - e a seus papéis volantes -, como Nicolo Nelli (1565) e Matthäus Franck (1565), que não só falaram do monstro, como também produziram imagem dele (HUE, 2004, p. 127). Atenhamo-nos a um fragmento do relato de Nicolo Nelli em que descreve o monstro e narra o sucesso de sua morte para, em seguida, cotejá-lo com trecho análogo do livro do próprio Gandavo. Segundo Nicolo Nelli (apud PAPAVERO; TEIXEIRA, 2007, p. 81):

Nel bresil di San Vicenzo nella città di Santes appresso la casa di Giorgio Ferando é apparso questo mostro sur la riua del mare uscito dell'acqua doue/cridando e facendo gran rumore 
si riuolgea per terra sopra l'erba; et ritrouandoli il figliolo del sudetto Giorgio in casa corse il mostro, et con la spada lo affronto anomosamente; e lo feri, et lui fu ferito dal mostro si, che tutti due cascorno in terra; et il giouane mori onde quelli del paese corsero al rumore/et con archi l'ammazarono. La misura del mostro é piedi 17 la pelle di color verde et pastosa come il uelluto e molle, le gambe o piedi gialli/il membro di carne umana, gl'occhi e la lingua come il foco.

Ao lermos o fragmento de Gandavo e ao cotejá-lo com aquele de Nelli, constatamos imediatamente que o mancebo valente, filho de capitão, o é de um tal Baltasar Ferreira, segundo Gandavo, e não de um Giorgio Ferando, como o declara Nelli; aqui, a precisão do nome é reforço do argumento histórico, porque uma personagem, não existente de fato, "ficta" - Giorgio Ferando -, é tornada "histórica" por precisão nominal: Baltasar Ferreira. Como Pero de Magalhães de Gandavo argumenta desde o início de sua exposição, a verdade é uma só, pois se há mais de uma possibilidade, não se trata nem de história, nem de seu complemento, a verdade fundada na autópsia. Há outra evidente contraposição entre o relato de Gandavo e aquele de Nelli, que respeita à sucedida morte ou não do filho do capitão Baltasar Ferreira: Nicolo Nelli afirma que o rapaz matou o monstro, mas foi, por seu turno, morto por ele; Gandavo assevera, por outro lado, que o jovem matou o monstro, foi atacado por ele, mas não morreu. O não ter morrido incrementa imensamente o caráter do jovem guerreiro e produz dele intensa amplificação elogiosa (CICERO, 1989, p. 173-185). Pero de Magalhães de Gandavo critica implicitamente ainda o fato de contemporâneos seus afirmarem que o monstro foi morto por nativos, e não pelo filho do capitão Baltasar Ferreira, como ele o declara, pois o monstro teria morrido de uma segunda estocada na cabeça que o mancebo lhe dera. A imagem da luta entre a besta e o filho do capitão, com a consequente morte do monstro, é incrivelmente vívida, narrada com linguagem chã, como demandavam, aliás, o gênero histórico e a oratória pública (CICERO, 1993, p. 357). Essa evidentia ou clareza discursiva, por seu turno, é amplificada com a visão da imagem do monstro fornecida a par dos relatos. Lembramos que o termo "descrição" faz alusão à enargeia, pois o descrito ou retratado verbalmente é aquilo que produz uma "imagem" da coisa, como pintura ou desenho. Assim, o autor se propõe fazer uma descrição visualizante do monstro, pondo sob os olhos dos leitores o tal ser fero e espantoso. Colocando-se em evidência por seus méritos de orador capaz de descrever o monstro, Gandavo minora as descrições feitas por outros que, segundo ele, não foram capazes de mostrar, com enargeia (vividez), a semelhança do horrendo aspecto da besta. Para tornar o seu discurso convincente e não despertar a incredulidade dos leitores, o autor leva em conta a questão da brevidade, como sugerem a Retórica, de Aristóteles, e, também, a Retórica a Alexandre, dentre outras. Vejamos como isso ocorre na continuação da narrativa:

Na capitania de Sam Vicente, sendo ja alta noite a horas em que todos começauam de se entregar ao sono, acertou de sair fora de casa huma India escraua do capitão: a qual lançando os olhos a huma varzea q está pegada com o mar, \& com a pouoaçam da mesma capitania, vio andar nella este monstro, mouendose de huma parte pera outra, com passos $\&$ meneos desusados, \& dando alguns hurros de quando em quando tam feos, que como pasmada \& quasi fora de si, se veo ao filho do mesmo capitam, cujo nome era Baltesar Ferreira, \& lhe deu conta do que vira, parecendolhe que era alguma visam diabolica [...] Entam se leuantou elle mui de pressa, \& lançou mão a huma espada que tinha junto de si, com a qual botou sómente em camisa pela porta fora [...]. E pondo os olhos naquella parte que ella the assinalou, vio confusamente o vulto do monstro ao longo da praya, sem poder diuisar o que era, por causa da noite lho impedir \& o monstro tambem ser cousa nam vista, $\&$ fora do parecer de todos os outros animaes (GANDAVO, 1576, p. 31).

Para narrar convincentemente, o autor informa-nos que o lugar da aparição do monstro estava deserto, haja vista que já era tarde e todos já se entregavam ao sono. Nesse ínterim, há a introdução dos personagens na narração: uma índia, escrava do capitão Baltasar Ferreira, e o filho do capitão. 
Nesse ponto, não nos esqueçamos da dignidade dos personagens. A primeira, sendo índia, estava na sua condição de escrava, e o segundo, o filho do capitão, na de um nobre. O cronista, então, segue com a narração, procurando fazer uma visualização imaginosa da cena, à medida que faz remissão a vários termos ligados ao campo da visão: a índia "lançou os olhos", "viu" andar um monstro. No primeiro caso, lançar os olhos significa projetar o olhar através do espaço. No segundo, o "ver" é perceber pela visão, enxergar. Essas são técnicas que redundam na enargeia, que faz ver a cena descrita. No caso em questão, a projeção do olhar não se restringe à índia do capitão, mas também aos leitores que veem a cena pelos olhos intelectuais do juízo. Assim, depois de detalhar o lugar onde a cena se desenrolou, uma várzea situada entre o mar e a povoação da Capitania de São Vicente, o autor diz que a índia viu o monstro se movimentando de uma parte a outra, com passos e gestos incomuns, próprios de um ser invulgar. Como não se tratava de um ser normal, não poderia ser descrito de maneira habitual. Daí Gandavo aludir aos "passos \& meneos desusados” do monstro. Além disso, o monstro soltava bramidos assustadores que fizeram com que a índia ficasse pasmada e quase fora de si. Sendo índia, a personagem não poderia ser descrita de outra maneira. Como era inferior ao nobre filho do capitão, só poderia demonstrar covardia diante da ferocidade do monstro. Em oposição à índia, o filho do capitão Baltasar Ferreira aparece como rapaz corajoso, merecedor de elogio por conta da força e bravura com que enfrenta o monstro. Este é descrito por Gandavo como feroz e assustador para revelar a bravura do filho do capitão, pois, quanto mais temerário o monstro, mais virtuoso se torna o rapaz que o enfrentou. Prosseguindo, a índia deu conta do que "viu" ao filho do capitão, sugerindo que teve uma "visão" diabólica. Novamente, a remissão à visão aparece duas vezes mais na citação, fazendo referência à evidentia. O monstro, a seguir, é comparado ao Diabo, como meio de se amplificar sua feiura. Por sua vez, o filho do capitão, varão corajoso e intrépido, sacou da espada que tinha junto de si e, em camisa, foi ao encontro do monstro. Esse trecho é muito interessante por evidenciar a dignidade do filho do capitão: sua linhagem é nobre; o instrumento que porta é uma espada, que tem junto de si. A espada revela que ele é um homem importante para o Reino, pois é um homem cujo ofício é o das armas. Ele é possuidor de uma grande virtude - a coragem - e, segundo Aristóteles, merece ser honrado, pois é útil aos homens na guerra e também na paz. Um traço da sua coragem é revelado pelo traje com que saiu para encontrar o monstro: em camisa. O mancebo não teve a preocupação de vestir uma armadura antes de enfrentar o perigo.

Dando sequência ao que diz a narração, o nobre filho do capitão pôs os olhos no lugar referido pela índia e viu confusamente o vulto do monstro na praia. Nesse ponto, o autor acumula novos termos ligados ao campo da visão: pôs os "olhos", "viu" confusamente, tornando clara a narração, assim como verossímil pela imitação dos topoi das autoridades. Nesse trecho, a evidentia é produzida por meio da visualização imaginosa da cena em que aparece o monstro. Ressaltamos, ainda, a preocupação do autor em descrever o lugar e o tempo: ao longo da praia e à noite, respectivamente. O excerto é finalizado com a ratificação de que o monstro era coisa incomum, que, ao contrário da preguiça e do peixe-boi, descritos anteriormente em seus livros, não poderia ser comparado a outros animais, por ser coisa nunca antes vista. Com isso, dizemos que Gandavo, por meio da repetição de termos "visualizantes", dá-nos uma amostra da perspicácia do seu engenho. Dando continuidade à sua narração, Gandavo descreve como se deu a morte do monstro pelas mãos do mancebo:

Nisto conheceo o mancebo q era aquillo cousa do mar, \& antes que nelle se metesse, acodio com muita presteza a tomarlhe a dianteira. E vendo o monstro que elle the embargaua o caminho, leuantouse direito pera cima como hum homem, fincado sobre as barbatanas do rabo, \& estando assi apar com elle, deulhe huma estocada pela barriga, \& dandolha no mesmo instante se desuiou pera huma parte com tanta velocidade, q nam pode o Monstro leualo debaixo de si: porem nam pouco afrontado, porque o grande torno de sangue q sahio da ferida, lhe deu no rosto com tanta força que quasi ficou sem nenhuma vista. E tanto que o Monstro se lançou em terra deixa o caminho que leuaua, \& assi ferido hurrando com a 
boca aberta sem nenhum medo, remeteo a elle, \& indo pera o tragar a vnhas \& a dentes, deulhe na cabeça huma cutilada muy grande: com a qual ficou ja muy debil, \& deixando sua vaã porfia, tornou entam a caminhar outra vez pera o mar. Neste tempo acodíram alguns escrauos aos gritos da India que estaua em vella: \& chegando a elle o tomáram todos ja quasi morto, \& dali o leuáram dentro á pouoaçam, onde esteue o dia seguinte á vista de toda gente da terra [...]. O retrato deste Monstro, he este q no fim do presente capitulo se mostra, tirado pelo natural. Era quinze palmos de comprido \& semeado de cabellos pelo corpo, \& no focinho tinha humas sedas mui grandes como bigodes (GANDAVO, 1576, p. 31-32).

No excerto acima, o cronista prossegue contando como procedeu o filho do capitão quando da notícia do monstro. Como nas narrações e descrições anteriores, há o acúmulo de termos ligados ao campo da visão, com vistas a pôr a coisa descrita sob os olhos dos leitores. Assim, o mancebo "viu" que o monstro era um animal do mar e, para não deixá-lo fugir, foi ágil em tomar-lhe a dianteira. Essa atitude é própria de um homem virtuoso, pois a coragem é própria de homens virtuosos. Dessa vez, a remissão à visão diz respeito ao monstro, que, ao "ver" que o rapaz vinha em sua direção, levantou-se e ficou como um homem, sobre as barbatanas do rabo. A comparação do monstro com o homem é curiosa à medida que demonstra que aquele se preparou para enfrentar o mancebo, ficando em posição idêntica à de um homem. Quando o monstro ficou em frente ao rapaz, este, bravamente, o atacou com um golpe de ponta da espada, instrumento levado por ele. $\mathrm{O}$ instrumento, como dissemos anteriormente, contribui para evidenciar a coragem e bravura do rapaz, que defendia a população da Capitania de São Vicente de um monstro perigoso. Como era sagaz, ao atingir o monstro, o mancebo não permitiu que aquele revidasse e, com grande velocidade, desviou-se para outra parte, de modo que o monstro não pôde atacá-lo. Não obstante, o sangue que saiu da ferida do monstro foi tanto, que atingiu o rosto do mancebo, deixando-o impossibilitado de ver. A exageração na quantidade de sangue contribui para ratificar o vigor do monstro e também o do rapaz que conseguiu ainda assim enfrentá-lo. Após a queda que o lançou em terra, o monstro voltou-se para o rapaz, urrando, com a boca aberta, sem medo, e, quando ia atacá-lo com unhas e dentes, recebeu, na cabeça, outro golpe de espada. Nesse trecho, o cronista figura o monstro como um animal intrépido que, mesmo depois de ser atacado, tentou revidar. A audácia do monstro é revelada pelas unhas e dentes, estruturas que podem funcionar como armas. Diante da coragem do mancebo, o monstro não se intimidou. Assim, a intrepidez do monstro é figurada pelo cronista a fim de evidenciar a coragem do rapaz que, mesmo diante do maior perigo, não arrefeceu. Com a última cutilada, o monstro enfraqueceu-se e, desistindo da disputa, tentou fugir para o mar. O cronista usa a expressão "vã porfia" para aludir à desistência do monstro de lutar com o mancebo. Isso significa que o animal, reconhecendo a intrepidez do rapaz, percebeu que seria vã qualquer tentativa de atingi-lo. Enquanto isso tudo acontecia, a índia escrava do capitão estava observando e, ao som dos seus gritos, acudiram outros escravos. Nesse passo, o autor novamente faz remissão à visão, quando diz que a índia estava "em vella". Essa amplificação da visão corrobora para que o efeito de vividez seja atingido, pondo sob os olhos do juízo o monstro descrito. Notemos desse trecho, ainda, que os escravos só chegaram até o monstro quando o mancebo já o tinha atingido mortalmente, o que implica dizer que o mérito pela morte do monstro é unicamente do mancebo. A função dos escravos foi levar o monstro já quase morto à povoação, para que ficasse à vista de toda a gente no dia seguinte.

Novamente, Gandavo faz outra remissão à visão ao desvelar que o monstro esteve à vista da população da Capitania depois de morto. Isso é complementado com a conclusão do autor, que diz que o retrato do monstro foi tirado pelo natural. A intenção de retratar o monstro implica a reprodução da imagem dele para leitores europeus, que não puderam vê-lo, como ele, e é complemento da descrição, que o põe diante dos olhos por meio de recursos discursivos. Quando o autor diz que o retrato foi tirado do natural, reitera a ideia aludida anteriormente de que falaria a verdade, que era uma só. Com isso, ele refuta qualquer semelhança com a fantasmagoria dos bestiários da época, desvelando a sua 
verdade sobre o monstro. Ele finaliza a descrição do monstro, especificando seu tamanho, quinze palmos de comprido, e complementa essa particularização da empiria ao discorrer sobre seu corpo e focinho, em que havia uns fios, como bigodes. A imagem discursiva, resultante da aplicação de procedimentos retóricos, pode até ser, como afirma Hansen, muita vez nonsense para nós (HANSEN, 2006, p. 92), mas nela se articulam técnicas de arte oratória e de escritura que eram eficientes para produzir a persuasão, paralelamente à afirmação do caráter testemunhal e ocular daquilo sobre o que se escrevia.

De modo complementar, dizemos que Gandavo produziu uma ekphrasis do monstro, posto que apresentou um retrato dele que pode ser compreendido como uma emulação verbal que compete com a pintura. O retrato do monstro, portanto, pode ser visto como a descrição de um quadro inexistente com vividez, ou enargeia. Na verdade, a descrição é produzida pelo cronista, que se vale de topoi conhecidos para apresentar uma imagem desconhecida e, por que não dizer, estranha ou maravilhosa, a qual compete discursivamente com uma pintura, numa emulação que nada tem a ver com repetição mecânica, mas rivaliza e tenta superar o emulado. Diante do exposto, reiteramos a habilidade do cronista que faz o retrato do monstro, valendo-se de preceitos críveis para narrar o incrível. Como atesta o próprio Gandavo $(1576$, p. 32): “[...] tudo se pode crer, por difficil que pareça: porque os segredos da natureza nam foram reuelados todos ao homem, pera que com razam possa negar, \& ter por impossiuel as cousas q não vio, nem de que nunqua teue noticia”.

Como ele ainda afirma, não se pode negar aquilo que não se viu; ver é condição fundamental para a composição do discurso histórico; os que não viram o Hipupiára podem, no entanto, sem tê-lo visto, crer na imagem que o cronista lhes apresenta, pois é o olho do cronista que ratifica a imagem, retifica as imagens falsas circulantes em seu tempo, e narra com veracidade o evento da aparição e morte do monstro. Normalmente, a descrição deveria partir de loci ou lugares comuns para ser composta, mas como o que nos é apresentado é coisa novíssima, o "narrador", que deveria expor "a coisa por meio da opinião sobre a coisa, com autoridade, clareza e nitidez, apresentando-a com enargeia" (HANSEN, 2007, p. 3), produz na verdade a opinião sobre a coisa, refutando opiniões concorrentes, porque falsas. Cabe apenas dizer que Gandavo parte sempre de quaestiones infinitae, para, em seguida, particularizá-las, determinando-as. 


\section{Referências}

ARISTÓTELES. Poética. Tradução, prefácio, introdução, comentário e apêndices de Eudoro de Sousa. Lisboa: Imprensa Nacional/Casa da Moeda, 1994.

ARISTÓTELES. Retórica a Alexandre. São Paulo: Edipro, 2012.

BURCKHARDT, Jacob. A cultura do Renascimento na Itália. São Paulo: Companhia das Letras, 2003.

CERTEAU, Michel de. Heterologies. Discourses on the Other. Minneapolis: University of Minnesota Press, 1986.

CICERO. Ad Herennium. With an English Translation by Henry Caplan. Cambridge: Harvard University Press, Loeb Classical Library, 1989.

CICERO. De Optimo Genere Oratorum. Cambridge: Harvard University Press, Loeb Classical Library, 1993, p. 347-381.

GANDAVO, Pero de Magalhães de. Historia da prouincia Sancta Cruz, a que ulgar mente chamamos Brasil: feita por Pero Magalhães de Gandauo, dirigida ao muito Illustre Sñor Do Lionis Pereira. Biblioteca do Museu do Escorial, Ms. IV. 28, 1576.

GANDAVO, Pero de Magalhães de. Historia da prouincia Sancta Cruz, a que ulgar mente chamamos Brasil: feita por Pero Magalhães de Gandauo, dirigida ao muito Illustre Sñor Do Lionis Pereira e Historia da prouincia Sãcta Cruz a que ulgarmente chamamos Brasil feita por Pero de Magalhães de Gandauo dirigida ao mui Illus ${ }^{\mathrm{mo}}$ Dom Lionis $\mathrm{P}^{\mathrm{a}}$ gouernador que foy de Malaca e das demais partes do Sul da India. Lisboa: Antônio Gonçalves, 1576.

GANDAVO, Pero Magalhães de. A primeira historia do Brasil - Historia da província Santa Cruz a que vulgarmente chamamos Brasil. Texto modernizado e notas de Sheila Moura Hue e Ronaldo Menegaz. Rio de Janeiro: Zahar, 2004.

GINZBURG. Carlo. A micro-história e outros ensaios. Tradução de António Narino. Lisboa: Difel, 1991.

HANSEN, João Adolfo. Agudezas Seiscentistas. In: Floema Especial, Vitória da Conquista, v. II, n. 2 A, p. 85-109, out. 2006.

HANSEN, João Adolfo. Categorias epidíticas da ekphrasis. Revista USP, v. 71, p. 85-105, 2007.

HUE, Sheila Moura. Imagens do Brasil para além de Gandavo. In: FRANÇA, Jean Marcel Carvalho; PEREIRA, Milena as Silveira. Por escrito: lições e relatos do mundo luso-brasileiro. São Carlos: Editora EduFSCAR, 2018. p. 207-224.

PAPAVERO, Nelson; FERREIRA, Dante Martins. A fauna de São Paulo nos séculos XVI a XVIII, nos textos dos viajantes, cronistas, missionários e relatos monçoeiros. São Paulo: Edusp, 2007.

MOREIRA, Marcello. Critica textualis in caelum revocata? Uma proposta de edição e estudo da tradição de Gregório de Matos e Guerra. São Paulo: Edusp, 2011.

STE. CROIX, G. E. M. Aristotle on History and Poetry - (Poetics, 9, 1451a 36-b11). In: RORTY, Amélie Oksenberg. Aristotle's Poetics. Princeton: Princeton University Press, 1992. p. 23-32).

VEYNE, Paul. Como se escreve a história. 4. ed. Brasília: Editora UnB, 1998.

WOODRUFF, Paul. Aristotle on Mimēsis. In: RORTY, Amélie Oksenberg. Aristotle's Poetics. Princeton: Princeton University Press, 1992. p. 73-93). 


\section{ANEXOS}

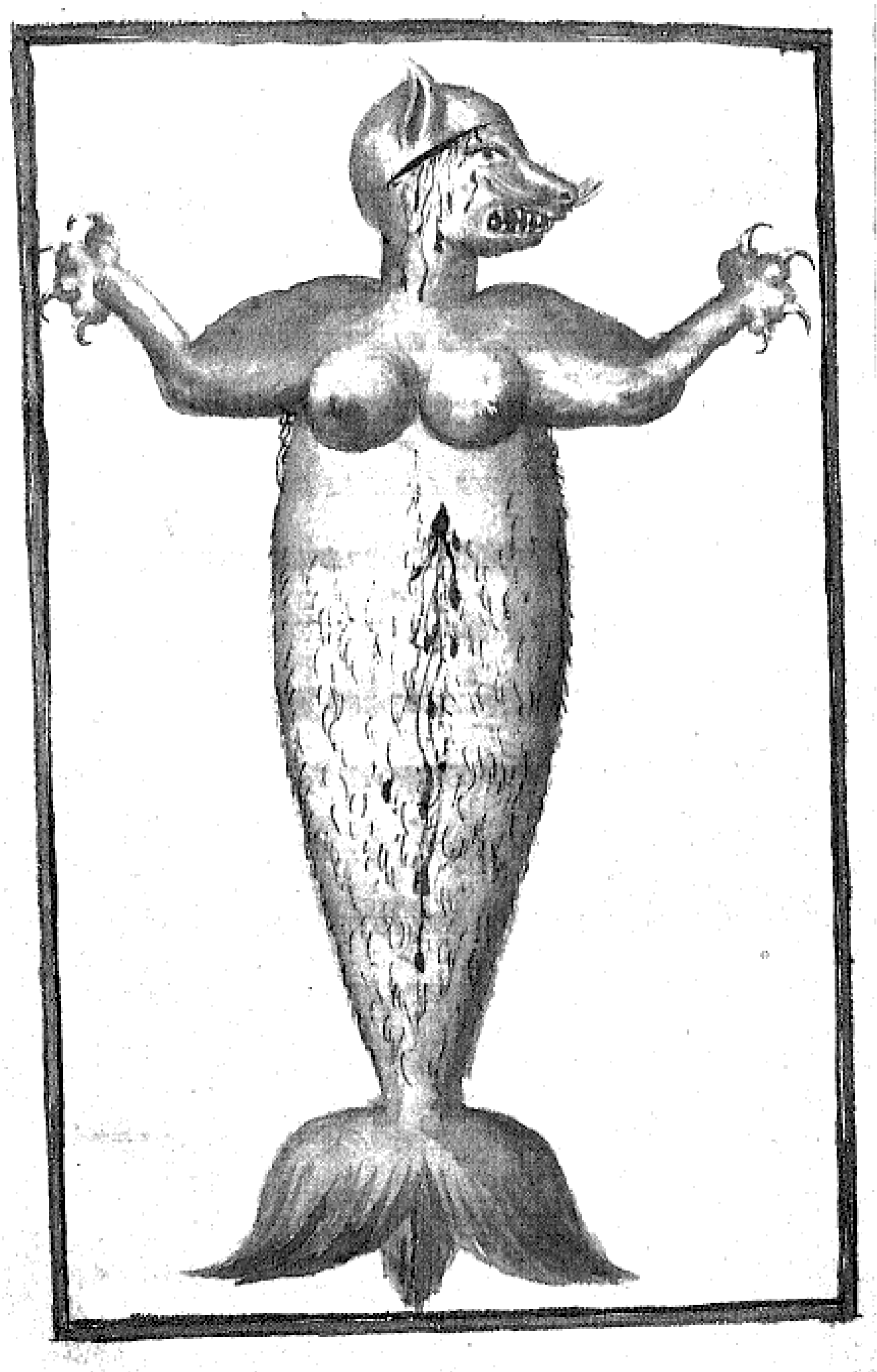

Imagem do monstro Hipupiára presente no manuscrito do texto de Gandavo: Historia da prouincia Sancta Cruz, a que ulgar mente chamamos Brasil, encontrado na Real Biblioteca do Mosteiro do Escorial, IV.28. 


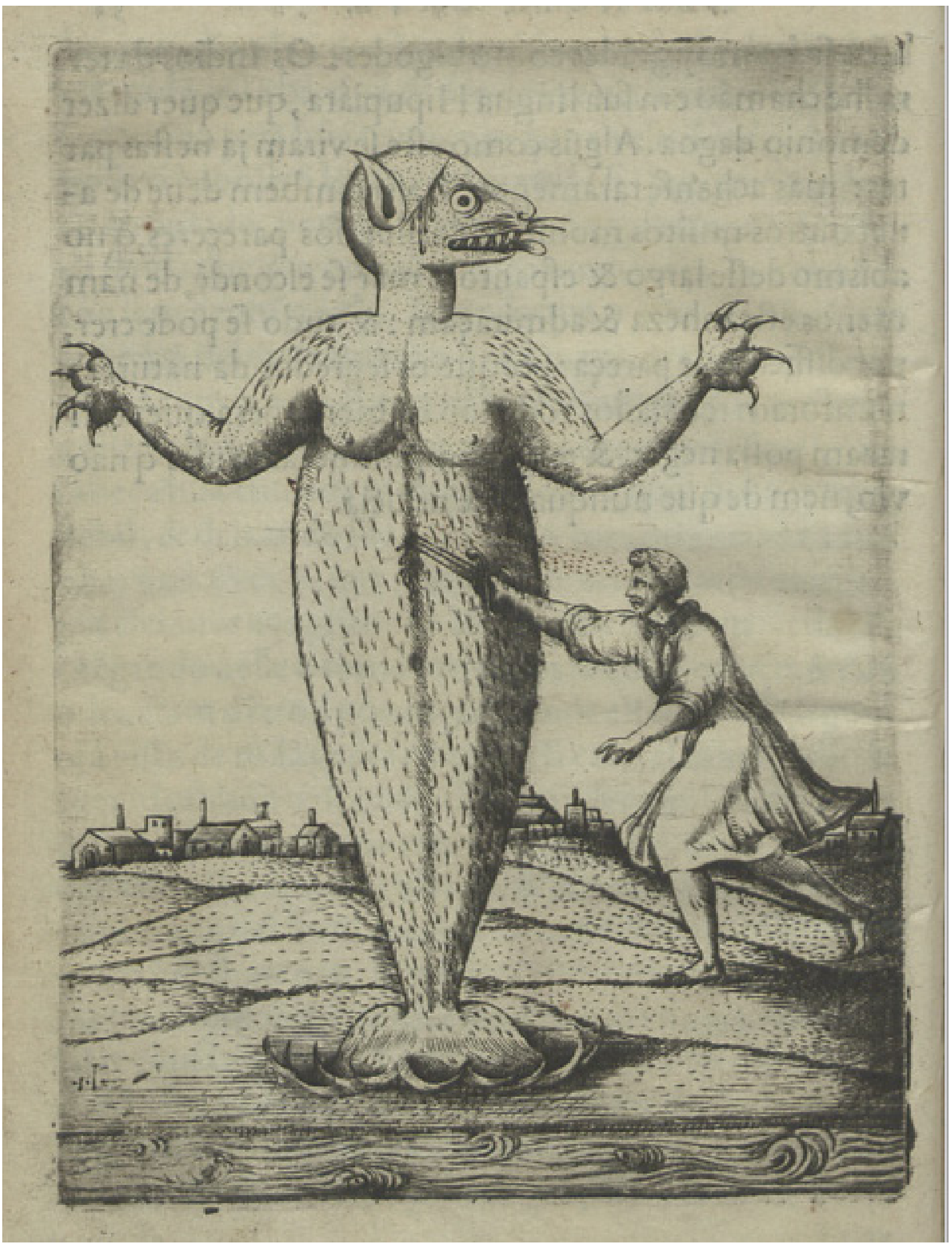

Imagem do monstro Hipupiára que aparece na versão definitiva do texto de Gandavo: Historia da prouincia Sancta Cruz, a que ulgar mente chamamos Brasil, impressa em Lisboa por Antônio Gonçalves em 1576. Encontrada na Biblioteca Nacional do Rio de Janeiro. 